\title{
mRNA Vaccines Against Infectious Diseases and Cancer
}

\author{
Alexander Meisel ${ }^{1}$, Steve Pascolo ${ }^{2 *}$
}

ABSTRACT

Synthetic mRNA acts as a template for synthesizing proteins, protein fragments, or peptides and now has many pharmaceutical applications. ${ }^{1,2}$ Coronavirus disease 2019 (COVID-19) due to infection with severe acute respiratory syndrome coronavirus 2 (SARS-CoV-2), a novel zoonotic RNA virus, has resulted in the rapid development of dedicated mRNA vaccines. ${ }^{3-5}$ This rapid $^{-1}$ response was made possible by using mRNA platforms that already existed for experimental vaccines against other infectious diseases and cancer. ${ }^{6-12}$ Carrier-based mRNA vaccines have been developed using lipid-based delivery, peptide-based delivery, polymer-based delivery, and cationic nano-emulsions, as well as dendritic cells. ${ }^{13}$ The mRNA vaccine leads to the expression of encoded antigens in antigen-presenting cells (APCs), generating both innate and adaptive immune responses. Future developments in mRNA therapy in oncology are expected to include adaptations in the routes of administration and co-delivery of multiple mRNAs with other anti-cancer treatments, such as immune checkpoint inhibitors (ICI), radiotherapy, or chemotherapy. In addition, advances in next-generation sequencing (NGS) technology allow the genome, exome, and transcriptome of a single cancer patient to be deciphered. This new knowledge about the diversity of epitopes in different tumors and corresponding specific $T$ cells has allowed the advancement of personalized cancer treatments. ${ }^{14}$ The article aims to present the rationale for the new therapeutic roles of mRNA vaccines, from COVID-19 and other infections to personalized oncology therapeutics.

Keywords: cancer, COVID-19, mRNA vaccine, SARS-CoV-2

\section{THE STRUCTURE AND DELIVERY OF THERAPEUTIC mRNA}

Synthetic mRNA acts as a template for translation of proteins, protein fragments, or peptides and has meanwhile found many pharmaceutical applications. ${ }^{1,15}$ Large-scale production of pharmaceutical-grade synthetic mRNA, mRNA optimization (for example the implementation of a very efficacious cap structure called CleanCap by Trilink ${ }^{16}$ ), and the combination with nanoparticle-based formulations increase functionality ${ }^{17,18}$. Transient and controlled production of encoded proteins from the mRNA template improves the safety and pharmacokinetic properties when compared with therapeutic recombinant DNA, viruses, or proteins. Figure 1 illustrates the structure and delivery of therapeutic mRNA using a lipid-based mRNA nanoparticle. ${ }^{1}$ The different mRNA delivery methods and structural elements can be "fine-tuned" to steer mRNA stability, translation, and the ability to activate an innate immune response. Recent developments in mRNA vaccines have been conducted in parallel with advances in cancer immunotherapy.

\section{mRNA VACCINES AGAINST SARS-COV-2 AND OTHER INFECTIOUS DISEASES}

From December 2019, reports emerged from Wuhan, China, of an epidemic of novel coronavirus infection. ${ }^{3}$ Within weeks, this infection reached the USA and Europe. ${ }^{4,19}$ Coronavirus disease 2019 (COVID-19) is caused by infection with severe acute respiratory syndrome coronavirus 2 (SARS-CoV-2), a novel zoonotic RNA virus. ${ }^{3}$ Currently, infection with SARS-CoV-2 has involved all countries of the world, and the pandemic is still uncontrolled. ${ }^{5}$ In fact, in August 2021, New Zealand was put under strict lockdown again after the country's first coronavirus case in 6 months was reported in the largest city of Auckland.
${ }^{1}$ Department of Nuclear Medicine University Hospital Zurich Zurich, Switzerland 2 Department of Dermatology University Hospital Zurich Zurich, Switzerland

${ }^{*}$ Corresponding author: PD Dr Steve Pascolo Department of Dermatology University Hospital Zurich Zurich, Switzerland Email: Steve.Pascolo@usz.ch

DOI: 10.36000/hbT.OH.2021.09.045 ISSN: 2673-2092 (Print) and 2673-2106 (Online)

This article was received on May 10, 2021.

This article was accepted on September 13, 2021.

This article was published on October 15, 2021.

Meisel A, Pascolo S. mRNA Vaccines Against Infectious Diseases and Cancer. healthbook TIMES Onco Hema. 2021:(9):24-31. 


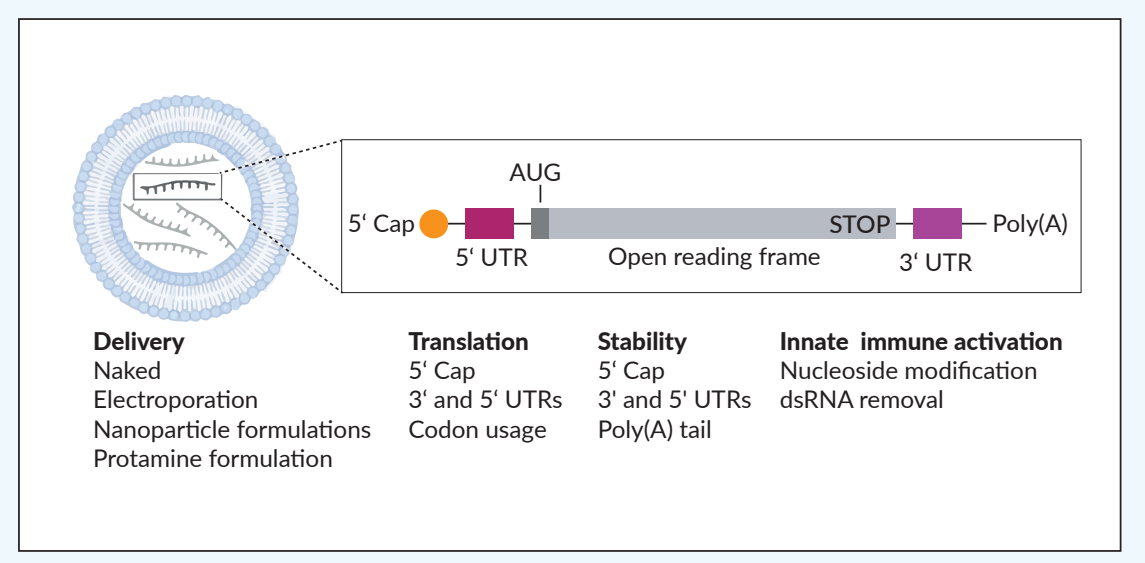

Figure 1. The structure and delivery of therapeutic mRNA. The lipid-based mRNA nanoparticle (left) and the synthetic mRNA (right) include a 5' cap, and $5^{\prime}$ and $3^{\prime}$ untranslated regions (UTRs), with a start codon that initiates the open reading frame (AUG), a stop codon, and a poly(A) tail. Different mRNA delivery methods and structural elements can be "fine-tuned" to affect mRNA stability, translation, and its effects on activating an innate immune response. Adapted from Beck et al. 2021. ${ }^{1}$
The pathogenesis of this new infection continues to be studied as new virus variants emerge and as long-term sequelae of infection, or "long-COVID", become recognized. A population-based cohort study in Switzerland has reported concerning numbers as well as striking gender differences, with longCOVID rates rising up to $43.0 \%$ in women and $31.5 \%$ in men. Alongside the increasing transmissibility and mortality associated with novel variants of concern, these results underline the requirement for protective immunity. Early in 2020, vaccine development began, with the first emergency authorizations for novel mRNA vaccine from the end of $2020 .^{6-12}$

Within a year after identifying SARS-CoV-2, Pfizer/BioNTech (Mainz, Germany) and Moderna (Cambridge, MA, USA) developed mRNA vaccines to SARS-CoV-2, BNT162b2 and mRNA-1273, respectively. ${ }^{6-9}$ Both consist of CleanCap ${ }^{\circ}$ capped and nucleoside-modified RNA vaccine with a lipid nanoparticle formulation, which encodes a "pre-fusion" stabilized, membrane-bound SARS-CoV-2 full-length spike protein. BNT162b2 is administered at a dose of $30 \mu \mathrm{g}$ followed by a second dose after 21 days. ${ }^{7}$ This mRNA vaccine received emergency use authorization (EUA) from the US Food and Drug Administration (FDA) in December $2020^{8}$, followed by the approval by Swissmedic in January $2021^{20}$. The mRNA1273 is administered at a dose of $100 \mu \mathrm{g}$ followed by a second dose after 28 days. This vaccine received FDA EUA in December $2020^{10}$, and Swissmedic approval in January $2021^{21}$.

Historically, vaccine development, the conduct of phase III randomized clinical trials, data analysis, and approval for these novel mRNA vaccines for COVID-19 were the most rapid for any new vaccine against a novel pathogen. ${ }^{6}$ This rapid response was made possible by using mRNA platforms that already existed for experimental vaccines against infectious disease (Table 1) and against cancer (Table 2), which have been available for the past two decades. ${ }^{1,11,12,22-24}$ and largely improved thanks notably to the optimization of liposomal for- mulations. ${ }^{17,18}$ As variants are spreading worldwide, studies are comparing the level of cross-neutralizing antibodies induced by classical BNT162b2 and ChAdOx1-S vaccinations with the heterologous prime and boost with ChAdOx1-S followed by BNT162b2, respectively. This study will analyze the safety and efficacy of the heterologous vaccination with ChAdOx1-S followed by BNT162b2. ${ }^{25}$ Recently, Pfizer and BioNTech have announced the submission of initial data to FDA to support booster dose of COVID-19 vaccine. The phase I safety and immunogenicity data show that the booster dose elicited significantly higher neutralizing antibody titers against the initial SARS-CoV-2 virus (wild-type), and the beta and delta variants compared to the levels observed after the two-dose primary series. Additionally, after the booster dose, neutralizing titers for variants were similar to wild-type. In fact, with the high levels of immune responses observed, a booster dose given within 6 to 12 months after the primary vaccination schedule may help maintain a high level of protection against COVID-19. ${ }^{26}$

\section{mRNA-BASED VACCINES FOR CANCER IMMUNOTHERAPY}

There are currently several vaccines that prevent infection with viruses associated with cancer, including those for human papillomavirus (HPV) and hepatitis B (HBV). ${ }^{27,28}$ However, the current rationale for developing cancer vaccines is to destroy established tumor cells rather than prevent cancer. ${ }^{1,27}$ So far, the promising results obtained with anti-cancer mRNA vaccines in preclinical developments were not supported by pivotal human clinical studies. However, during the past decade, development in multiomic analysis platforms, immune checkpoint inhibitors, and improved delivery systems, as well as an increased understanding of the tumor microenvironment, including antigen-presenting cells (APCs) and factors suppressing the immune response to malignant cells, have increased the potential of anti-cancer mRNA vaccines. ${ }^{29}$ Despite mRNA vaccines, synthetic mRNA coding for specific therapeutic molecules $\left(\right.$ receptors ${ }^{30}$, cytokines $^{31}$, or antibodies ${ }^{32,33}$ ) can be used for anti-cancer therapies. ${ }^{34}$ 


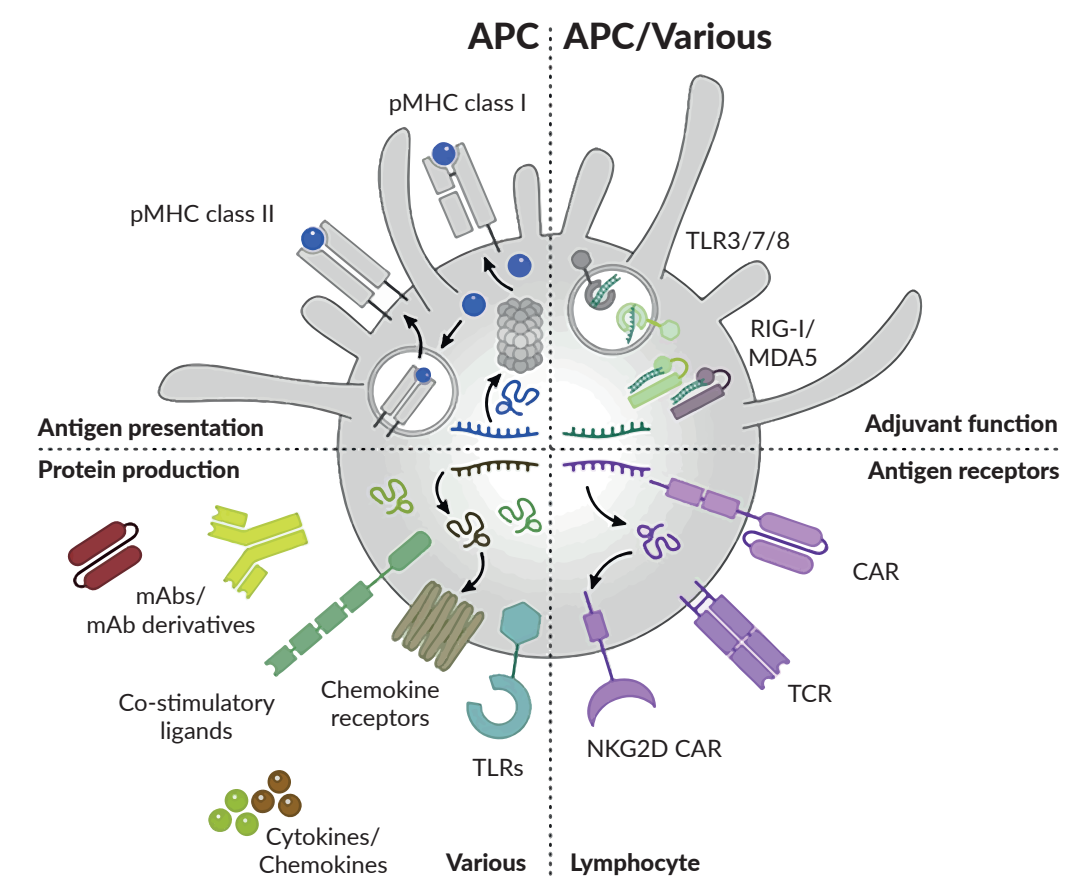

Figure 2. The basis for cancer immunotherapy and mRNA vaccines.

The mRNA cancer vaccine may deliver key cancer antigens to antigen-presenting cells (APCs) in the context of major histocompatibility complex (MHC) class I and II. The innate immune response can be activated by binding to pattern recognition receptors (PRRs) expressed by the APCs and specific for mRNA. Other utilisation of mRNA (not discussed in this review), include therapies where receptors (e.g., chimeric antigen receptor [CAR] or T cell receptor [TCR]) can be expressed in lymphocytes by transfection of mRNA or anti-cancer proteins

(cytokines, antibodies, immunomodulating receptors) can be expressed by injection (for example directly in the tumor tissue) of synthetic mRNA. TLR, Toll-like receptor; CAR, chimeric antigen receptor; TCR, T cell receptor; $\mathrm{mAb}$, monoclonal antibody; MDA5, melanoma differentiation-associated protein 5; pMHC, peptide-major histocompatibility complex; NKG2D, natural killer group 2D; RIG-I, retinoic acid-inducible gene. Adapted from Beck et al. 2021.

Figure 2 illustrates several mechanisms of anti-cancer immunomodulation by synthetic mRNA. ${ }^{1}$ Following vaccination, the isolated mRNA or vehicle-loaded mRNA vaccine leads to the expression of tumor antigens in APCs, which are presented to $\mathrm{T}$ cells in the context of the major histocompatibility complex (MHC) molecules. ${ }^{1,13,29,35}$ Both innate and adaptive immune responses can be generated as presented in the upper part. Passive immunity can be provided by synthetic mRNA (coding e.g., antibodies or immune receptors) as presented in the lower part. This review focuses only on the active immunity induced by mRNA vaccines.

The initial development of mRNA vaccines in oncology ${ }^{36}$ was limited by low mRNA immunogenicity. ${ }^{29}$ This limitation has been overcome by improving mRNA design (extremities, untranslated regions and coding sequence) and the carrier (mostly liposomes $\left.{ }^{17,18}\right)$, with the advantages of mRNA vaccines being their safety and nowadays efficacy, along with the ability to manufacture them on a mass scale. ${ }^{29,35}$ Currently, mRNA vaccines can be coupled with an immunologic adjuvant, which enhances the body's immune response to antigens, and improved delivery strategies have been developed. ${ }^{13,37,38}$ Recent improvements in mRNA vaccines also include the modulation of mRNA-induced innate and adaptive immunity. ${ }^{13,35}$ The use of naked mRNA without a delivery vector may not provide a sufficient immune response as shown in the worldwide first clinical studies evaluating synthetic mRNA vaccines. ${ }^{22,39}$ Therefore, carrier-based mRNA vaccines have been developed, using lipid-based delivery, peptide-based delivery, polymer-based delivery, and cationic nano-emulsions, as well as dendritic cells. ${ }^{13}$

\section{CURRENT STATUS OF MRNA VACCINES FOR CANCER IMMUNOTHERAPY}

Future developments in mRNA vaccines in oncology are expected to include adaptations in the routes of administration and co-delivery of multiple mRNA vaccines with other therapeutic agents, such as checkpoint inhibitors as well as individualized vaccines next-generation sequencing of cancer biopsies and healthy tissue allows to define mutations in the tumor for each patient and generate an adequate individualized vaccine). ${ }^{13,35}$ Table 2 summarizes the current status of mRNA vaccines in oncology that are undergoing or have completed randomized clinical trials. The following recent clinical trials of mRNA vaccines in cancer therapy have shown promising results in patients with solid tumors.

\section{The Lipo-MERIT trial (non-modified $m R N A$,}

NCT02410733): BNT111

BNT111 is a liposomal mRNA (RNA-LPX) vaccine that targets four non-mutated, tumor-associated melanoma antigens (NY-ESO-1, MAGE-A3, tyrosinase, and TPTE), and is administered intravenously. ${ }^{40-42}$ Interim data were recently published from an ongoing, phase I, first-in-human, dose-escalation clinical trial that included 89 patients with advanced unresectable melanoma treated with repeated doses of BNT111 ranging from $7.2 \mu \mathrm{g}$ to $400 \mu \mathrm{g}$. $^{40}$ The most common adverse events (AEs) were mild-to-moderate, transient flu-like symptoms such as pyrexia and chills. The efficacy of BNT111 was assessed by imaging of metastatic lesions before and after vaccination in a subset of 42 checkpoint inhibitor-experienced patients with radiologically evaluable melanoma. ${ }^{42}$ 
mRNA Vaccines and Cancer

Table 1. Active and completed clinical trials of mRNA vaccines in the treatment of viral infections. Adapted from Wang et al. $2021 .{ }^{29}$

\begin{tabular}{|c|c|c|c|c|}
\hline Infection & Phase & Status & Drug treatment & NCT number \\
\hline SARS-CoV-2 & $\begin{array}{l}\text { I } \\
\text { III } \\
\text { I/II/III } \\
\text { I } \\
\text { I } \\
\text { I }\end{array}$ & $\begin{array}{l}\text { Active } \\
\text { Active } \\
\text { Active } \\
\text { Recruiting } \\
\text { Active } \\
\text { Active } \\
\text { Active } \\
\text { Not yet } \\
\text { recruiting }\end{array}$ & $\begin{array}{l}\text { BNT162b1 + placebo } \\
\text { CVnCoV vaccine + placebo } \\
\text { mRNA-1273 + placebo } \\
\text { BNT162b1 + BNT162b2 } \\
\text { CVnCoV } \\
\text { mRNA-1273 } \\
\text { mRNA-1273 + placebo } \\
2 \text { doses of BNT162b2 or one dose of BNT162b2s01 }\end{array}$ & $\begin{array}{l}\text { NCT04523571 } \\
\text { NCT04449276 } \\
\text { NCT04470427 } \\
\text { NCT04368728 } \\
\text { NCT04515147 } \\
\text { NCT04283461 } \\
\text { NCT04405076 } \\
\text { NCT04949490 }\end{array}$ \\
\hline Rabies & $\begin{array}{l}1 \\
1\end{array}$ & $\begin{array}{l}\text { Completed } \\
\text { Active }\end{array}$ & $\begin{array}{l}\text { CV7201 mRNA encoding the rabies virus glycoprotein } \\
\text { Rabipur }^{\circledR}\end{array}$ & $\begin{array}{l}\text { NCT02241135 } \\
\text { NCT03713086 }\end{array}$ \\
\hline HIV-1 & $\begin{array}{l}\text { I/II } \\
\text { I }\end{array}$ & $\begin{array}{l}\text { Completed } \\
\text { Terminated } \\
\text { Completed }\end{array}$ & $\begin{array}{l}\text { mRNA-transfected autologous DCs+/-autologous DCs } \\
\text { with no mRNA transfection } \\
\text { TriMix mRNA+/-HIV mRNA } \\
\text { iHIVARNA-01 + TriMix+/-Placebo }\end{array}$ & $\begin{array}{l}\text { NCT00833781 } \\
\text { NCT02413645 } \\
\text { NCT02888756 }\end{array}$ \\
\hline Zika virus & । & $\begin{array}{l}\text { Completed } \\
\text { Active }\end{array}$ & $\begin{array}{l}\text { mRNA-1325 + placebo } \\
\text { mRNA-1893 + placebo }\end{array}$ & $\begin{array}{l}\text { NCT03014089 } \\
\text { NCT04064905 }\end{array}$ \\
\hline Tuberculosis & । & Completed & GSK 692342 & NCT01669096 \\
\hline Ebola virus & । & Completed & $\begin{array}{l}\text { two separate mRNAs encoding two Zaire strain Ebola } \\
\text { glycoproteins, respectively }\end{array}$ & NCT02485912 \\
\hline Influenza & $\begin{array}{l}1 \\
\mid / I 1\end{array}$ & $\begin{array}{l}\text { Completed } \\
\text { Recruiting }\end{array}$ & $\begin{array}{l}\text { VAL-506440 + placebo } \\
\text { mRNA-1010 + placebo }\end{array}$ & $\begin{array}{l}\text { NCT03076385 } \\
\text { NCT04956575 }\end{array}$ \\
\hline Cytomegalovirus & I & $\begin{array}{l}\text { Completed } \\
\text { Recruiting }\end{array}$ & $\begin{array}{l}\text { mRNA-1647 + placebo } \\
\text { mRNA-1647 + placebo }\end{array}$ & $\begin{array}{l}\text { NCT03382405 } \\
\text { NCT04232280 }\end{array}$ \\
\hline $\begin{array}{l}\text { Respiratory } \\
\text { syncytial virus } \\
\text { (RSV) vaccine }\end{array}$ & । & Recruiting & mRNA-1345 + placebo & NCT04528719 \\
\hline $\begin{array}{l}\text { Human } \\
\text { Metapneumovirus } \\
\text { and Human } \\
\text { Parainfluenza } \\
\text { Infection }\end{array}$ & । & $\begin{array}{l}\text { Completed } \\
\text { Recruiting }\end{array}$ & $\begin{array}{l}\text { mRNA-1653 + placebo } \\
\text { mRNA-1653 + placebo }\end{array}$ & $\begin{array}{l}\text { NCT03392389 } \\
\text { NCT04144348 }\end{array}$ \\
\hline
\end{tabular}

At data cutoff, of 25 patients treated with BNT111 monotherapy, 3 achieved a partial response (PR), 7 had stable disease (SD), and 1 had complete metabolic remission of metastatic lesions. Of 17 patients treated with BNT111 plus anti-PD-1 therapy 6, experienced a PR. Treatment with BNT111 also re- sulted in the expansion and activation of circulating tumor-antigen-specific $\mathrm{T}$ cells with memory function exhibiting strong cytotoxic activity against tumor cells. Vaccine-induced antigen-specific memory $\mathrm{T}$ cells persisted for more than one year under continuous monthly vaccination. 


\section{healthbook TIMES Oncology Hematology}

Table 2. Active and completed clinical trials of mRNA vaccines in the treatment of solid malignant tumors. Adapted from Wang et al. $2021 .{ }^{29}$

\begin{tabular}{|c|c|c|c|c|}
\hline Tumor type & Phase & Status & Drug treatment & NCT number \\
\hline $\begin{array}{l}\text { Non-small cell lung } \\
\text { cancer (NSCLC) }\end{array}$ & $\begin{array}{l}|/| \mid \\
|/|||\end{array}$ & $\begin{array}{l}\text { Recruiting } \\
\text { Recruiting } \\
\text { Recruiting }\end{array}$ & $\begin{array}{l}\text { BI } 1361849 \text { (CV9202) + Durvalumab+/-Tremelimumab } \\
\text { Personalized mRNA vaccine encoding neoantigen } \\
\text { Suppressor of cytokine signaling (SOCS) 1, MUC1 and Survivin } \\
\text { mRNA-loaded DC + cytokine-induced killer cells }\end{array}$ & $\begin{array}{l}\text { NCT03164772 } \\
\text { NCT03908671 } \\
\text { NCT0268868 }\end{array}$ \\
\hline Melanoma & $\begin{array}{l}\text { I/I } \\
\text { I } \\
\text { I/II } \\
\text { | } \\
\text { | } \\
\text { I| } \\
\text { I/I } \\
\text { | } \\
\text { || } \\
\text { | }\end{array}$ & $\begin{array}{l}\text { Completed } \\
\text { Completed } \\
\text { Completed } \\
\text { Completed } \\
\text { Completed } \\
\text { Completed } \\
\text { Completed } \\
\text { Completed } \\
\text { Completed } \\
\text { Recruiting } \\
\text { Active } \\
\text { Terminated } \\
\text { Active }\end{array}$ & $\begin{array}{l}\text { mRNA+GM-CSF } \\
\text { DCs transfected with hTERT, survivin and p53 } \\
\text { Dendritic cells electroporated with mRNA encoding gp100 and } \\
\text { tyrosinase } \\
\text { TriMix-DC } \\
\text { DCs loaded with mRNA encoding tumor-associated antigens } \\
\text { gp100 and tyrosinase+/ -cisplatinum } \\
\text { mRNA coding for melanoma associated antigens+GM- } \\
\text { CSF mRNA-transfected DCs + IL-2 } \\
\text { autologous dendritic cell vaccine by mRNA } \\
\text { Electroporation Autologous dendritic cell vaccine } \\
\text { mRNA-4157 + pembrolizumab } \\
\text { Autologous Langerhans-type dendritic cells electroporated with } \\
\text { mRNA encoding a tumor-associated antigen } \\
\text { Lipo-MERIT } \\
\text { Dendritic cells - transfected with hTERT-, survivin- and } \\
\text { tumor cell-derived mRNA+ex vivo T cell expansion and } \\
\text { (NCI)-4650, an mRNA-based, personalized cancer } \\
\text { vaccine Autologous dendritic cells with mRNA }\end{array}$ & $\begin{array}{l}\text { NCT00204607 } \\
\text { NCT00978913 } \\
\text { NCT00940004 } \\
\text { NCT01066390 } \\
\text { NCT02285413 } \\
\text { NCT00204516 } \\
\text { NCT01278940 } \\
\text { NCT01530698 } \\
\text { NCT00243529 } \\
\text { NCT03897881 } \\
\text { NCT01456104 } \\
\text { NCT03480152 } \\
\text { NCT02410733 }\end{array}$ \\
\hline Ovarian cancer & $\begin{array}{l}1 \\
1 / 11\end{array}$ & $\begin{array}{l}\text { Recruiting } \\
\text { Terminated } \\
\text { Terminated }\end{array}$ & $\begin{array}{l}\text { W_ova1 + carboplatin/paclitaxel } \\
\text { DC-006 vaccine } \\
\text { DCs loaded with TERT-mRNA and survivin-peptide }\end{array}$ & $\begin{array}{l}\text { NCT04163094 } \\
\text { NCT01334047 } \\
\text { NCT01456065 }\end{array}$ \\
\hline Prostate cancer & $\begin{array}{l}\text { I } \\
\text { I/I } \\
\text { I } \\
\text { II } \\
\text { I/I }\end{array}$ & $\begin{array}{l}\text { Completed } \\
\text { Completed } \\
\text { Completed } \\
\text { Active } \\
\text { Withdrawn } \\
\text { Terminated } \\
\text { Unknown }\end{array}$ & $\begin{array}{l}\text { mRNA-transfected dendritic cells } \\
\text { DCs transfected with PSA, PAP, survivin and hTERT } \\
\text { mRNA+docetaxel } \\
\text { DC loaded with protamine/mRNA encoding keyhole limpet } \\
\text { hemocyanin (KLH) + DC loading with MHC I binding peptides, } \\
\text { NY-ESO-1 and MUC1 PepTivator }{ }^{\circledR} \\
\text { Dendritic cell vaccine } \\
\text { Human telomerase reverse transcriptase mRNA (hTERT mRNA) } \\
\text { transfected dendritic cell } \\
\text { CV9104 } \\
\text { Peptide vaccine+montanide ISA-51+/-GM-CSF+/- } \\
\text { imiquimod+/-mRNA/protamin }\end{array}$ & $\begin{array}{l}\text { NCT01278914 } \\
\text { NCT01446731 } \\
\text { NCT02692976 } \\
\text { NCT01197625 } \\
\text { NCT01153113 } \\
\text { NCT02140138 } \\
\text { NCT02452307 }\end{array}$ \\
\hline $\begin{array}{l}\text { Gastrointestinal } \\
\text { cancer }\end{array}$ & $\begin{array}{l}|/ I| \\
\mid / I I\end{array}$ & $\begin{array}{l}\text { Completed } \\
\text { Completed } \\
\text { Recruiting }\end{array}$ & $\begin{array}{l}\text { CEA mRNA-loaded DCs } \\
\text { Personalized mRNA vaccine encoding neoantigen } \\
\text { Adenovirus-transfected autologous DCs + CIK cells }\end{array}$ & $\begin{array}{l}\text { NCT00228189 } \\
\text { NCT03468244 } \\
\text { NCT02693236 }\end{array}$ \\
\hline
\end{tabular}




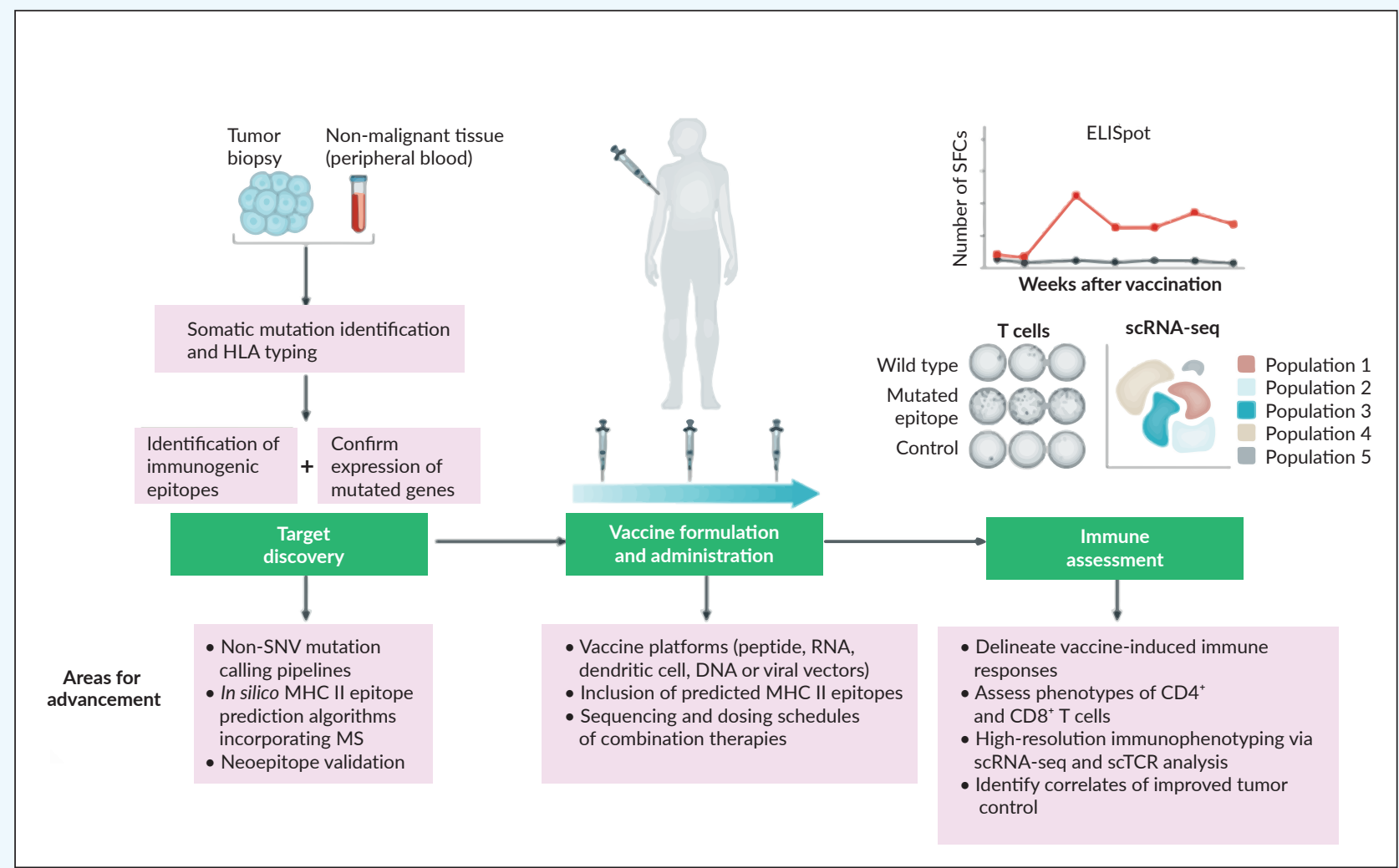

Figure 3. Algorithm-based identification of neoantigens for use in therapeutic vaccines. MHC II, major histocompatibility complex class ॥; MS, mass spectrometry; scRNA-seq, single-cell RNA sequencing; scTCR, single-cell T cell receptor; SFC, spot-forming cell; SNV, single-nucleotide variant. Modified from Blass and Ott 2021. ${ }^{51}$

\section{RO7198457 (non-modified mRNA, NCT03289962): \\ BNT122}

RO7198457, an individualized mRNA vaccine that contains up to 20 patient-specific neoantigens, has been investigated as monotherapy and in combination with atezolizumab, a PDL1 inhibitor, in patients with locally advanced or metastatic solid tumors, including breast cancer, prostate cancer, ovarian cancer, melanoma, non-small cell lung cancer (NSCLC), bladder cancer, and colorectal cancer (CRC). ${ }^{43,44}$ In a phase Ia dose-escalation study, 29 patients (median lines of prior therapies: 5) received $\mathrm{RO} 7198457$ at doses ranging from $25 \mu \mathrm{g}$ to $100 \mu \mathrm{g} .^{43}$ Of 26 evaluable patients, one patient with gastric cancer and metastatic liver lesions had a confirmed complete response $(\mathrm{CR})$ that was ongoing for more than 10 months, while 12 patients achieved SD. Regarding safety, adverse events (AE) were mostly of grade 1-2 and included infusion-related reaction (IRR)/cytokine release syndrome (CRS), fatigue, nausea, and diarrhea. IRR/CRS were transient and reversible and presented primarily as grade $1-2$ chills and fever. In the phase Ib portion of the study, 132 patients received RO7198457 at doses ranging from $15 \mu \mathrm{g}-50 \mu \mathrm{g}$ in combination with atezolizumab. ${ }^{44}$ The median number of prior therapies was 3 and $39 \%$ of patients received prior immunotherapy. Of 108 patients, one patient had a CR and 8 had PRs, while almost half of the patients achieved SD. Neoantigen-specific T-cell responses were observed in 77\% of the patients. Most AEs were of grade 1-2 and included IRR, CRS, and influenza-like illness, fatigue, nausea and diarrhea.
RO7198457 is currently being investigated in combination with pembrolizumab, a PD-1 inhibitor, versus pembrolizumab alone in patients with previously untreated advanced melanoma in the phase II IMCODE001 trial. ${ }^{45}$

\section{The KEYNOTE-603 trial (modified mRNA, NCT03313778): $m R N A-4157$}

The KEYNOTE-603 trial evaluated the safety and efficacy of mRNA-4157 as monotherapy $(n=16)$ or in combination with pembrolizumab (200 mg intravenously) $(n=63)$ in patients with solid tumors. ${ }^{28}$ mRNA-4157 is a lipid encapsulated modified mRNA-based individualized cancer vaccine encoding neoantigens. Patients receive up to 9 cycles of mRNA- 4157 by intramuscular injection at up to $1 \mathrm{mg}$ alone or in combination with pembrolizumab. An updated analysis showed that in the head and neck squamous cell carcinoma (HNSCC) group $(n=10)$ treated with the vaccine plus pembrolizumab, the overall response rate (ORR) was 50\%, with 2 patients achieving $\mathrm{CR}$ and 3 achieving $\mathrm{PR}$, all of which were ongoing. In addition, 4 patients had SD, resulting in a disease control rate of $90 \%$. Median progression-free survival (PFS) was 9.8 months versus 2 months in pembrolizumab monotherapy. In the group of patients with microsatellite-stable (MSS) CRC $(\mathrm{n}=17)$, only 1 SD was reported and within 6 weeks of receiving the vaccine, 10 patients with MSS-CRC progressed, and 1 completed all doses. Only low-grade and reversible treatment-related AEs were observed. 
The KEYNOTE-942 trial (modified mRNA, NCT03897881): mRNA-4157

In 2019, a phase I multicenter study reported on the safety, tolerability, and immunogenicity of mRNA-4157 alone in melanoma patients with resected tumors $(n=13)$ and combination with pembrolizumab in patients with advanced or metastatic cancer $(n=20) .{ }^{46}$ At a median follow-up of 8 months, the results showed that 11 patients on the monotherapy arm remained disease-free. In the combination arm, 1 out of 20 patients had a CR, 5 had PR and 6 patients had SD. All treatment-related AEs were reversible and of low grade, and no drug-related serious AEs or AEs grade $\geq 3$ have been observed.

\section{THE FUTURE OF MRNA VACCINES}

The accelerated development, manufacture, clinical trials, and authorizations of mRNA vaccines have been propelled in the past year by the COVID-19 pandemic. An outcome from the current interest in mRNA vaccines highlighted their potential role in personalized medicine and therapeutics in oncology. All three major mRNA vaccine companies: BioNTech, CureVac and Moderna, have several ongoing clinical studies testing mRNA (modified or non-modified) vaccines against viral disease as well as vaccines against cancer. The latter uses a larger variety of technologies: the site of injection can be intradermal, intramuscular or intravenous, the mRNA can be coding for shared tumor antigens or be individualized to encode patient-specific mutations (Figure 3) and the vaccine can be used in combination with other anti-cancer treatments (mostly immune checkpoint inhibitors). It can be expected that some of those approaches will soon lead to the approval of anti-cancer mRNA vaccine modalities. The future will bring increasing collaboration between academic institutions, large pharmaceutical companies, and small biotech companies to develop and trial new mRNA vaccines. For example, Gritstone Oncology, a California-based biotechnology company, recently announced their findings from two phase I studies, which investigated two RNA products, viral prime plus self-amplifying RNA boost, GRANITE (GO-004), a personalized therapy with 20 tumor-specific neoantigens, and SLATE (GO-005), an off-the-shelf shared neoantigen therapy that includes 20 driver mutations in genes such as KRAS and TP53. ${ }^{47}$ In an early analysis, GRANITE showed good tolerability and robust neoantigen-specific CD8-positive T-cell responses consistently induced across all patients. ${ }^{47}$ GRANITE will be further evaluated in combination with immune checkpoint inhibitors nivolumab and ipilimumab in the phase II portion of the study, with an expanded cohort for patients with MSS-CRC and gastroesophageal cancer who have progressed on chemotherapy regimens. SLATE also demonstrated induction of CD8-positive T cells against multiple KRAS driver mutations, but strong responses were observed only in a subset of patients. The phase II portion of the GO-005 study will therefore assess the therapy in combination with nivolumab plus ipilimumab in patients with NSCLC harboring KRAS mutations who have progressed on prior checkpoint inhibitor therapy and patients with TP53-mutated advanced cancers.

The increasing optimization and clinical testing of mRNA vaccines mostly driven by the three major companies (CureVac created in 2000, BioNTech in 2008 and Moderna in 2010) led to the approval of very efficacious anti-COVID vaccines within a record time of one year from the disclosure of the sequence of SARS-CoV-2. Although the first studies of mRNA vaccines in human were performed in cancer patients ${ }^{22,48,49}$, there is still no approved anti-cancer mRNA vaccine. However, results obtained lately in phase I studies are very promising and combination treatment (mostly immune checkpoint inhibitors combined with generic or individualized anti-cancer mRNA vaccines) are expected to be efficacious and soon approved. Meanwhile, accelerated by the COVID-19, mRNA vaccines against several pathogens are intensively developed to protect against infectious diseases not yet prevented by vaccines (e.g., infection by the respiratory syncytial virus [RSV], cytomegalovirus [CMV], human immunodeficiency virus [HIV], or malaria), or where the available vaccines may pose production/ efficacy/safety issues [e.g., seasonal flu, rabies]). The mRNA vaccines being easy and quick to produce as well as vegan (production requires only bacterial-derived products and chemicals, no animal products), have now proven to be very safe and efficacious in the context of the COVID-19 pandemic. It has boosted the development of this vaccine format against many infectious agents and against cancer as well as to control autoimmunity (there, the vaccine specifically induces tolerance in the immune cells $\left.s^{50}\right)$. The versatility of mRNA vaccines offers a very broad spectrum of utilizations. Thus, it is expected that mRNA vaccines will, within the next year, offer new potent and safe medicaments against a growing number of diseases.

\section{CONCLUSIONS}

- mRNA vaccines to prevent infectious disease and treat solid malignant tumors have undergone clinical development and clinical trials for several years.

- During the COVID-19 pandemic, clinical development, clinical trials, and regulatory approvals of mRNA vaccines to SARS-CoV-2 have been accelerated.

- mRNA vaccines in individualized oncology therapy rely on tumor tissue for gene sequencing to compare the patient's normal transcriptome with their tumor.

- A growing number of mRNA vaccines are expected to be validated against a broad spectrum of infectious diseases and cancers in the near future.

\section{CONFLICT OF INTEREST}

The authors declare no conflict of interest. 
REFERENCES

1. Beck JD, Reidenbach D, Salomon N, et al. mRNA therapeutics in cancer immunotherapy. Mol Cancer. 2021;20(1):69. doi:10.1186/s12943-021-01348-0 2. Jia L, Mao Y, Ji Q, Dersh D, Yewdell JW, Qian S-B. Decoding mRNA translatability and stability from the 5' UTR Nat Struct Mol Biol. 2020;27(9):814-821. doi:10.1038/ s41594-020-0465-x

3. Zhu N, Zhang D, Wang W, et al. A Novel Coronavirus from Patients with Pneumonia in China, 2019. N Engl J Med. 2020;382(8):727-733. doi:10.1056/NEJMoa2001017

4. Holshue ML, DeBolt C, Lindquist S, et al. First Case of 2019 Novel Coronavirus in the United States. N Engl J Med. 2020;382(10):929-936. doi:10.1056/NEJMoa2001191

5. COVID-19 Dashboard by the Center for Systems Science and Engineering (CSSE) at Johns Hopkins University. Johns Hopkins University Coronavirus Resource Centre. Johns Hopkins University Coronavirus Resource Centre.
[Accessed 26 April 2021]. Available from: https://coronavirus.jhu.edu/map.html.

6. AACR Virtual Meeting on COVID-19 and Cancer: "Lightspeed" Vaccine Development-How Did They Do It?. American Association for Cancer Research. [Accessed 26 April 2021]. Available from: https://www.aacr.org/ blog/2021/02/16/aacr-virtual-meeting-on-covid-19-andcancer-lightspeed-vaccine-development-how-did-they-doit/.

7. Polack FP, Thomas SJ, Kitchin N, et al. Safety and Efficacy of the BNT162b2 mRNA Covid-19 Vaccine. $N$ Engl J Med. 2020;383(27):2603-2615. doi:10.1056/NEJMoa2034577

8. Pfizer-BioNTech COVID-19 Vaccine. Food and Drug Administration. [Accessed 26 April 2021]. Available from: https://www.fda.gov/emergency-preparedness-and-response/coronavirus-disease-2019-covid-19/pfizer-bionsponse/coronavirus-
tech-covid-19-vaccine.

9. Baden LR, El Sahly HM, Essink B, et al. Efficacy and Safety of the mRNA-1273 SARS-CoV-2 Vaccine. $N$ Engl J Med. 2021;384(5):403-416. doi:10.1056/NEJMoa2035389

10. FACT SHEET FOR HEALTHCARE PROVIDERS ADMINISTERING VACCINE (VACCINATION PROVIDERS). Food and Drug Administration. [Accessed 26 April 2020]. Available from: https://www. fda.gov/media/144637/download.

11. Verbeke R, Lentacker I, De Smedt SC, Dewitte H. The dawn of mRNA vaccines: The COVID-19 case. $J$ Control Release. 2021;333:511-520. doi:10.1016/j.jconrel.2021.03.043

12. Dolgin E. How COVID unlocked the power of RNA vaccines. Nature. 2021;589(7841):189-191. doi:10.1038/ d41586-021-00019-w

13. Kim J, Eygeris Y, Gupta M, Sahay G. Self-assembled mRNA vaccines. Adv Drug Deliv Rev. 2021;170:83-112. doi:10.1016/j.addr.2020.12.014

14. Heine A, Juranek S, Brossart P. Clinical and immunological effects of mRNA vaccines in malignant diseases. $\mathrm{Mol}$ Cancer. 2021;20(1):52. doi:10.1186/s12943-021-01339-1 15. Pascolo S. Messenger RNA-based vaccines. Expert Opin Biol Ther. 2004;4(8):1285-1294. doi: $10.1517 / 14712598.4 .8 .1285$

16. Henderson JM, Ujita A, Hill E, et al. Cap 1 Messenger RNA Synthesis with Co-transcriptional CleanCap ${ }^{\circ}$ Analog by In Vitro Transcription. Curr Protoc. 2021;1(2):e39 doi:10.1002/cpz1.39

17. Ibba ML, Ciccone G, Esposito CL, Catuogno S, Giangrande PH. Advances in mRNA non-viral delivery approaches. Adv Drug Deliv Rev. 2021:113930. doi:10.1016/j.addr.2021.113930

18. Hou X, Zaks T, Langer R, Dong Y. Lipid nanoparticles for mRNA delivery. Nat Rev Mater. 2021:1-17. doi:10.1038/s41578-021-00358-0
19. Spiteri G, Fielding J, Diercke M, et al. First cases of coronavirus disease 2019 (COVID-19) in the WHO European Region, 24 January to 21 February 2020. Euro Surveill. 2020;25(9). doi:10.2807/1560-7917. ES.2020.25.9.2000178

20. COMIRNATY ${ }^{\circ}$. Product information. Swissmedic. [Accessed May 2021]. Available from: www.swissmedicinfo.ch

21. COVID-19 Vaccine Moderna. Product information. Swissmedic. [Accessed May 2021]. Available from: www. swissmedicinfo.ch.

22. Weide B, Carralot JP, Reese A, et al. Results of the firs phase I/II clinical vaccination trial with direct injection of mRNA. J Immunother. 2008;31(2):180-188. doi:10.1097/ CJI.0b013e31815ce501

23. Pipeline. Product Candidates. BioNTech. [Accessed 26 April 2021]. Available from: https://biontech.de/science/pipeline.

24. Moderna's Pipeline. Moderna. [Accessed 26 Apri 2021]. Available from: https://www.modernatx.com/pipe line.

25. Heterologous SARS-CoV-2 Vaccination With ChAdOx-1 and BNT162b2 (HeVacc). ClinicalTrials.gov. [Accessed August 2021]. Available from: https://www.clinicaltrials.gov/ct2/show/NCT04907331 ? cond=BNT162b28 draw $=2 \&$ rank $=14$.

26. Pfizer and BioNTech Announce Submission of Initia Data to U.S. FDA to Support Booster Dose of COVID-19 Vaccine. Press release. BioNTech. [Accessed August 2021]. Available from: https://investors.biontech.de/news-releases/news-release-details/pfizer-and-biontech-announcesubmission-initial-data-us-fda.

27. Paston SJ, Brentville VA, Symonds P, Durran LG. Cancer Vaccines, Adjuvants, and Delivery Systems. Front Immunol. 2021;12:627932. doi:10.3389 fimmu. 2021.627932

28. Lei J, Ploner A, Elfström KM, et al. HPV Vaccination and the Risk of Invasive Cervical Cancer. $N$ Engl J Med. 2020;383(14):1340-1348. doi:10.1056/NEJMoa1917338 29. Wang Y, Zhang Z, Luo J, Han X, Wei Y, Wei X. mRNA vaccine: a potential therapeutic strategy. Mol Cancer. 2021;20(1):33. doi:10.1186/s12943-021-01311-z

30. Beatty GL, Haas AR, Maus MV, et al. Mesothelin-specific chimeric antigen receptor mRNA-engineered T cell induce anti-tumor activity in solid malignancies. Cancer Immunol Res. 2014:2(2):112-120. doi:10.1158/2326 6066. CIR-13-0170

31. Van Lint S, Renmans D, Broos K, et al. Intratumora Delivery of TriMix mRNA Results in T-cell Activation by Cross-Presenting Dendritic Cells. Cancer Immunol Res. 2016;4(2):146-156. doi:10.1158/2326-6066.CIR-150163

32. Thran M, Mukherjee J, Pönisch M, et al. mRNA mediates passive vaccination against infectious agents, toxins, and tumors. EMBO Mol Med. 2017:9(10):1434-1447. doi: $10.15252 / \mathrm{emmm} .201707678$

33. Stadler CR, Bähr-Mahmud H, Celik L, et al. Elimination of large tumors in mice by mRNA-encoded bispecific antibodies. Nat Med. 2017;23(7):815-817. doi:10.1038 nm. 4356

34. Pardi N, Hogan MJ, Porter FW, Weissman D. mRNA vaccines - a new era in vaccinology. Nat Rev Drug Discov. 2018:17(4):261-279. doi:10.1038/nrd.2017.243

35. Miao L, Zhang Y, Huang L. mRNA vaccine for cance immunotherapy. Mol Cancer. 2021;20(1):41. doi:10.1186/ s12943-021-01335-5

36. Conry RM, LoBuglio AF, Wright $\mathrm{M}$, et al. Characterization of a messenger RNA polynucleotide vaccine vecto Cancer Res. 1995;55(7):1397-1400.

37. Kranz LM, Diken M, Haas H, et al. Systemic RNA delivery to dendritic cells exploits antiviral defence fo cancer immunotherapy. Nature. 2016;534(7607):396-401. doi: $10.1038 /$ nature 18300

38. Carralot J-P, Probst J, Hoerr I, et al. Polarization of im munity induced by direct injection of naked sequence-stabilized mRNA vaccines. Cell Mol Life Sci. 2004;61(18):24182424. doi:10.1007/s00018-004-4255-0

39. Rittig SM, Haentschel M, Weimer KJ, et al. Intradermal vaccinations with RNA coding for TAA generate CD8+ and CD4+ immune responses and induce clinical 999. doi: $10.1038 / \mathrm{mt} .2010 .289$

40. Sahin U, Oehm P, Derhovanessian E, et al. An RNA vaccine drives immunity in checkpoint-inhibitortreated melanoma. Nature. 2020;585(7823):107-112. doi:10.1038/s41586-020-2537-9

41. Evaluation of the Safety and Tolerability of i.v. Admiistration of a Cancer Vaccine in Patients With Advaced Melanoma (Lipo-MERIT). ClinicalTrils gov. [Accessed 26 April 2021]. Available from: https://clinicaltrials.gov/ ct/show/NCT02410733.

42. BioNTech Publishes Data from mRNA-based BNT111 FixVac Melanoma Trial in Nature. BioNTech July 2020. [Accessed May 2021]. Available from: https:// investors.biontech.de/news-releases/news-release-details/ biontech-publishes-data-mrna-based-bnt111-fixvac-melanoma-trial.

43. Braiteh F, LoRusso P, Balmanoukian A, et al. Abstract C169: A phase Ia study to evaluate RO7198457, an individualized neoantigen specific immunotherapy (iNeST), in patients with locally advanced or metastatic solid tumors. Cancer Res. 2020;80(suppl 16):CT169. doi:10.1158/1538 7445.AM2020-CT169

44. Lopez JS, Camidge R, Iafolla M, et al. Abstract CT301 A phase Ib study to evaluate RO7198457, an individualized neoantigen specific immunotherapy (iNeST), in combinaly advanced or metastatic solid tumors. Cancer Res. 2020;80(supp 16. CT301. doi:10.1158/1538-7445.AM2020-CT301 45. A Study to Evaluate The Efficacy And Safety O RO7198457 In Combination With Pembrolizumab Versus Pembrolizumab Alone In Participants With Previously Untreated Advanced Melanoma. (IMCODE001). ClinicalTrails.gov [Accessed 26 April 2021]. Available from https://clinicaltrials.gov/ct2/show/NCT03815058.

46. Burris HA, Patel MR, Cho DC, et al. A phase I multicenter study to assess the safety, tolerability, and resected solid tumors and in combination with pembrolizumab in patients with unresectable solid tumors. J Clin Oncol. 2019;37(15_suppl):2523-2523. doi:10.1200/ JCO.2019.37.15_suppl.2523

47. Corporate Presentation. Gritstone. [Accessed 26 April 2021]. Available from: https://ir.gritstoneoncologycom/ static-files/15857056-7494 $41 /$ drace0-44026 604210.

48. Weide B, Pascolo S, Scheel B, et a Direct Injection of Protamine-protected mRNA: Results of a Phase 1/2 Vaccination Trial in Metastatic Melanoma $\mathrm{Pa}$ tients. J Immunother. 2009;32(5):498-507. doi:10.1097/ CJI.0b013e3181a00068

49. Rettig L, Haen SP, Bittermann AG, et al. Particle size and activation threshold: a new dimension of dange signaling. Blood. 2010;115(22):4533-4541. doi:10.1182/ blood-2009-11-247817

50. Krienke C, Kolb L, Diken E, et al. A noninflammatory mRNA vaccine for treatment of experimental autoimmune encephalomyelitis. Science. 2021;371(6525):145-153 doi: $10.1126 /$ science.aay3638

51. Blass E, Ott PA. Advances in the development of personalized neoantigen-based therapeutic cancer vaccines. Nat Rev Clin Oncol. 2021;18(4):215-229. doi:10.1038 s41571-020-00460-2 